\title{
Polluted Leisure and Blue Spaces: More-than-human concerns in Fukushima
}

\begin{abstract}
Following a magnitude 9 earthquake on 11 March 2011, a tsunami swept across the coast of Japan. The devastation was complete and incomprehensible. Thousands of lives were lost and homes destroyed. The earthquake and tsunami disabled the Tokyo Electric Power Company's (Tepco) Fukushima Daiichi Nuclear Power Plant causing a nuclear accident. Subsequently, pollution in the form of radiation and concrete seawalls more powerfully influence how blue spaces (seas, oceans, rivers, lakes, and other waterways), health, sport, and leisure compose in Fukushima. In this article I reflect on some fieldwork experiences while considering 'polluted leisure' at this site. My argument is that pollution complicates any health-led blue spaces discourse that attributes positive transformations achieved during leisure-orientated sport in these spaces. Any accretion of health and wellbeing manifested in blue spaces is shown to simultaneously involve declension, within immediate and/or distant proximity. What may be happening 'here' will be affecting what happens 'over there.' Pollution ironically 'makes it clear' that we are not in charge of wellbeing, health, nature-based sport, and blue spaces correlations on this polluted planet.
\end{abstract}

Keywords: pollution, leisure, blue spaces, health, extreme sport, surfing

Acknowledgements: TBA (anonymised)

\section{Article: (8043 including references; excluding abstract)}

\section{Introduction}

Following a magnitude 9 earthquake on 11 March 2011, a tsunami swept across the coastal region. The force of the tsunami "turned cities and villages along the $500 \mathrm{~km}$ coastline of Tōhoku [a coastal region of the island of Honshu that includes the prefecture of Fukushima] to "mass piles of rubble, empty parks, and sunken land inundated with sea water" (Kato, 2013, p. 201). Thousands of lives were lost and homes destroyed. The earthquake and tsunami disabled the Tokyo Electric Power Company's (Tepco) Fukushima Daiichi Nuclear Power Plant, causing a nuclear accident. The power plant's three cores melted as the power failure meant that water could not be pumped around the reactors. Seawater was used to cool the reactors, resulting in contaminated water. In mid-March, major releases of airborne radionuclides occurred. ${ }^{1}$ High-level radiation was also leaked into the sea.

In this article I reflect on some fieldwork experiences at this site and how pollution can complicate any positive correlations between nature-based sports, blue spaces, and health/wellbeing. The term 'blue spaces' has been used by environmental and social psychologists to refer to seas, oceans, rivers, lakes, and other waterways 
(Gammon \& Jarratt, 2019). My attention had been drawn to Fukushima by a newspaper article about surfers returning to the coastal zone (familiarly called Hamadōri) (Lafforgue, 2016). Surfers were some of the first people to return to the area post-evacuation to continue riding waves there, as well as contribute to reconstruction of the area (McCurry, 2019).

My argument in this article is that more attention needs to be paid to how pollution interrupts correlations between blue spaces, sport, and health/wellbeing. The ubiquity of pollution means it is necessary to reckon with how sport in blue spaces is orientated through 'polluted leisure.' By the term 'polluted leisure' I mean the embodied, sensorial, emotional, intellectual, spatial, and technological busyness of pollution - material and social; harmful and non-harmful; actual and perceived - occurring through leisure (Evers, 2019). Leisure is understood here to be a temporary state of mind (and embodied experience) tied to a volitional undertaking of an activity that an enthusiast deems worthwhile. ${ }^{2}$ Polluted leisure means that encounters with blue spaces (e.g. through leisure-orientated sport) will not only result in therapeutic and health accretion but can simultaneously involve declension both here and 'over there'. My example here is the nature-based sport of surfing. ${ }^{3}$

Surfing has been variously classified as "alternative," "action," "adventure," "lifestyle," and "extreme" sport. ${ }^{4}$ Sports that fall into these categories all share an emphasis on interaction with 'nature. ${ }^{5}$ Surfing is known for being an archetypal nature-based sport (Booth, 2018). A growing body of literature argues that such sports can positively transform social, psychological, and physical health and wellbeing. ${ }^{6}$ For instance, it is claimed that they can foster autonomy, promote physical activity, facilitate social belonging, provide opportunities to learn about fear and anxiety, nurture resilience, mend self-esteem, improve self-efficacy, raise self-confidence, overcome trauma, support environmental sensibilities, heighten spirituality, help manage anxiety, as well as cultivate humility and courage through an experience of nature that inculcates its centrality to a fulfilling life (Anderson, 2009; Brymer, 2009; Brymer \& Schweitzer, 2013 Clough et al., 2016; Gilchrist \& Wheaton, 2017; Humberstone, 2011; Immonen et al., 2017; Olive, 2016 Taylor, 2007; Thorpe \& Chawansky, 2016; Thorpe \& Rinehart, 2013; Wheaton et al., 2017).7 It would be easy to assume such sports are a 'cure all', even though they are not. The arguments for the potential benefits intermingle with an influential discourse proposing that human encounters with nature result in the same positive transformations (Hartig et al., 2014).

More recently, blue spaces have been caught up in this positive nature-health correlation discourse. There now exists a health-led blue spaces discourse (Britton et al., 2018; Gascon et al., 2017; Foley et al., 2019). Britton et al. (2018) deliver a health-led definition of 'blue spaces' as referring to "all visible outdoor, natural surface waters with potential for the promotion of human health and wellbeing” (p. 2). In a study of swimmers, Ronan Foley 
(2017) explains that such correlations are experienced as a ‘therapeutic accretion' that occurs as they affectively, imaginatively, and emotionally encounter watery places. Given the correlations of health, wellbeing, and blue spaces, therapy and 'social good' surfing programs have been tied to the health-led blue spaces discourse (Caddick et al., 2015; Clapham et al., 2014; Wheaton et al., 2017). These programs are use surfing to achieve positive social, psychological, and physical health transformations. The National Health Service in the United Kingdom prescribes surfing to achieve such transformations. However, the way that pollution complicates these correlations is overlooked.

\section{More-than-human}

To establish how pollution complicates correlations between surfing, health, wellbeing, and blue spaces I proceed through a 'more-than-human' theoretical paradigm. Feminist cultural geographers Ruth Panelli (2010), Sarah Whatmore (2002, 2006), and Elspeth Probyn $(2014,2016)$ explain that a 'more-than-human' paradigm directs attention to how humans and nonhumans co-create truth(s) and realities. ${ }^{8}$ There is concrescence - "growing together” - from the 'inbetween' (Deleuze \& Guattari, 2004). According to Richard Grusin (2015), we can think of the nonhuman as "animals, plants, organisms, climatic systems, technologies, or ecosystems" (p. x). I add to Grusin's list: pollution. The more-than-human paradigm connects into theoretical and conceptual threads of vital materialism and agential realism which argue that matter matters (Barad, 2007; Bennett, 2010). That is, the material world is "vibrant" and contributes to any agency, co-constituting practice and meaning-making. ${ }^{9} \mathrm{I}$ focus on materiality in this article, however the more-than-human paradigm includes exploring relationships with multiple sentient species (e.g. animals) (Lorimer, 2010; Probyn, 2016). ${ }^{10}$ While the more-than-human paradigm critiques anthropocentrism, it maintains attention to the enduring production of human subjectivities, These subjectivities are understood to proceed by way of "intersectional" (e.g. race, sex, gender, species, class, caste, religion, ethnicity) oppressions and unjust ecological realities (Crenshaw, 1989; Haraway, 2016). ${ }^{11}$

\section{Methodology}

In 2017, as part of an interdisciplinary research team from Wakayama University (Japan) and Newcastle University (UK), I had the opportunity to travel to Fukushima to investigate the polluted leisure of surfing. Other members of the team had made multiple trips to Fukushima. Researchers from Wakayama University provided travel, access, and translation assistance. They were also research collaborators. ${ }^{12}$ Local surfers we met expressed positive sentiments about our presence. We arrived six years post-disaster and were inquiring about their 'serious leisure,' which they were happy to talk about (Stebbins, 2007). ${ }^{13}$ Team members and I took notes, photographs, video, and audio both on land and in the sea. Such a multi-media approach is useful in how it expands relationships 
and bandwidths beyond human senses, allowing more-than-human research to occur (Evers, 2016; Vannini, 2015).

My time spent at the site only amounts to one week, as I am currently in the early stages of my research into polluted leisure. Consequently, what follows is not an articulation of local surfer perspectives about relationships between surfing, pollution, health, and blue spaces. I cannot determine this, especially in the whole context of their continuing lives and culture. Further, I am proceeding from a very particular and partial standpoint as a visiting white western male, a perspective which shapes my understanding (Harding, 2014). Nevertheless, it has proven analytically productive to critically and reflexively research through myself and nonhuman stimuli experienced during fieldwork. Such a process can enable researchers to identify and examine transformative moments in wider material and socio-political processes (Probyn, 1993, 2016; Olive, 2019; Wright et al., 2012).

\section{Fukushima}

On 11 March 2011, following an earthquake, a tsunami damaged the TEPCO Fukushima Daiichi Nuclear Power Plant. Subsequently, radioactive material, including radioactive iodine-131 (Is) and radioactive cesium (Cs) isotopes, was released into the atmosphere and the Pacific Ocean (Christoudias \& Lelieveld, 2013). Most radiation was released into the atmosphere and ocean in the immediate aftermath of the Fukushima disaster. Hundreds of thousands of people were evacuated. Many people are now settled elsewhere, although surfers were some of the first to return. In a video made by the International Olympic Committee about surfing in Fukushima, one surfer points out that "we had no option but to leave here ... we re-realized this ocean is an integral part of our soul."14

Some critical surf scholars have argued that surfers and their concomitant meaning-making, embodiment, and existence are co-created with blue space ecologies - water, reef, flesh, sand, surfboards, the moon, society, energy, jetties, rocks, currents, and much more (Anderson, 2012; Booth, 2018; Britton, 2019; Evers, 2009; Ingersoll, 2016; Olive, 2016). Pollution is also part and parcel of these blue spaces. Surfers go surfing in sewage, and face high health risks as a water user group (Harding et al., 2015; Hart, 2016; Leonard et al., 2018; Neal, 2016). Surfing is polluted leisure (Evers, 2019).

When we arrived in Fukushima we noticed that official decontamination (josen) efforts were still ongoing in the places where the surfers were going surfing. Despite its imperceptibility to the human senses, radiation became evident through the countless black plastic bags filled with radioactive topsoil piled in large fields, along roads, and at the beach. The soil had become matter 'out of place,' dirty dirt. As anthropologist Mary Douglas (1966) explains, pollution involves a socially-driven "systematic ordering and classification of matter" (p. 35). Mind you, here we see how the classificatory system is reliant on the vicissitudes of radiation that co-creates the dirt as dirty. Pollution is a more-than-human process, not simply social and not simply material. 
Recently it has been found that radioactive particles became stored in subterranean brackish groundwater beneath beaches, where the cesium stuck to the sand which acted like a 'sponge' (Sanial et al., 2018). The cesium becomes 'unstuck' when mixed with seawater, so it continues to be released by waves and tides (Ibid). Ongoing release from groundwater means radiation is elevated in some near-shore areas (Ibid). In 2012 the World Health Organization estimated that there is low public health risk from radiation. However, as the groundwater example shows, ongoing research continues to identify problematic sites of deposit in coastal liminal zones that could be dangerous. As such, these deposits will complicate any possible therapeutic and health accretion gained by surfers through encounters with the blue space. Health declension may be occurring for the surfers of Fukushima, whether they are immediately aware of this or not. At the very least, uncertainty affects any sense of wellbeing surfers seek through this blue space.

Such pollution of blue spaces is not isolated to Fukushima. All blue spaces are polluted to varying degrees (for example, see Dasgupta et al., 2018; Muir \& Rose, 2007; Vane et al., 2015; Yang et al., 2016; Neimanis, 2018). In fact, this is a "permanently polluted world" (Liboiron et al., 2018, p. 332). Pollution is ecological. When something is called "ecological" it signifies a "necessary implication in a network of relations, to mark its persistent tendency to enter into a working system" that is "more or less mobile, more or less transient, more or less conflictual" (Bennett, 2004, p. 365). Blue spaces are now what Anna Lora-Wainwright (2017) calls “toxic natures." This concept refers to how "if pollution is part and parcel of nature, its bodily effects also come to include pollution" thus affecting biological, sociological, and psychological health and wellbeing (p. xxiv).

The Japanese government has a lot at stake when it comes to the seaside Daiichi power plant - politically and economically - given that 30\% of Japan's electricity comes from nuclear power (Miyazawa, 2018). The Tōhoku region of the island of Honshu (of which the Fukushima prefecture is a part) has 14 nuclear power plants, of which 10 are in Fukushima prefecture (Ibid). The building of this amount of nuclear power plants in Tōhoku is entangled with a history of the region being an "internal colony of Japan since the inception of the modern Japanese government" and subsequently an economic, social, and cultural subordinate (Ibid, p. 338). The people have been represented as "uncivilized, immoral, indolent, and unsanitary people who were different from the normal Japanese people" (Ibid, p. 338).

The people of Tōhoku are, using Douglas's (1966) theory of pollution, discursively constructed as 'pollution.' Declaring someone 'dirty' has been used as a way to mark out and safeguard a particular ordering of a society (Ibid). Eradicating those who are 'dirty' involves classifying them, as well as the organising and policing of borders and boundaries to signify who belongs or does not belong - who is considered to be valued or not valued, 
good or bad, acceptable or unacceptable. Pollution functions as an "exclusionary discourse" and is tied to inequalities based on race, age, ethnicity, place, class, nation, gender, and more (Taylor, 2014). We can see this exclusionary discourse at work in blue spaces. As Hannah Pitt (2018) argues, blue spaces are linked to social discomfort and unequal socio-economic barriers to participation (e.g. cultural, ethnic, racial, gendered, economic). The discomfort and barriers shape any interpretation and experience of therapy, health, and wellbeing. ${ }^{15}$ However, the many ways in which material and social pollution are entwined in blue spaces is being discounted. ${ }^{16}$

Our research team found evidence of discrimination against Fukushima surfers, with some mentioning that they experienced such discrimination when they moved elsewhere and travelled. People coming from Fukushima are experiencing sabetsu (discrimination) due to actual and perceived proximity to unsafe radiation levels (Aoki, 2013). Multiple reports exist about people being ostracised (Ibid). Cultural comparisons are made to bibakusha (atomic bomb-affected people of Hiroshima and Nagasaki). The discrimination affects school experiences, marriage, and employment (Ibid). Maeda and Oe (2017) have found that those living in or coming from Fukushima have to negotiate a public stigma of being 'contaminated.' Like the dirt in the black plastic bags, they have been classified as 'matter out of place' when not in Fukushima.

The stake the Japanese government has in the nuclear industry, the region's historically fraught relationship with that government, and a stigma of contamination all complicate interpretations of 'acceptable' radiation levels. Living with toxic natures involves negotiating diverse, competing, and sometimes contradicting "languages of valuation" (Lora-Wainwright, 2017, p. xxix). Professional surfer David Kinoshita explains, “The government monitored the release reports about safe levels of radiation and have said the ocean is safe but the fact is no one really knows about radiation ... the results are more likely be felt [sic] in 10 or 20 years from now" (McClean, 2018, p. 65). A post-3/11 systematic literature review of qualitative research about uncertainty and risk pertaining to radiation in Fukushima has found that this has caused distress and anxiety (Takebayashi et al., 2017). Beck and Willms (2004), following the Chernobyl disaster, found that levels of stress and anxiety rose not necessarily because of the radiation but more because people felt that they "were hanging from the marionette strings of these experts and institutions who continually contradicted each other" (p. 117). The stress and anxiety prompted people to undertake their own research, undertake new tasks, and learn new skills to determine their valuation of risk and what they can do to mitigate it (Ibid). Everyday strategies can become what Lora-Wainwright (2017) calls “resigned activism." This concept

encapsulates a spectrum of perceptions and practices comprising acts that may fit the conventional label of collective environmental contention ... but it also includes less confrontational and more-individualized or 
family-orientated strategies at minimizing pollution in one's immediate surroundings; closing the windows at night to limit exposure to fumes; wearing masks; buying bottled water; send children and pregnant women to live elsewhere ... defending one's own work as less harmful than that of others. (p. xxvii)

While Fukushima is not directly comparable to Chernobyl, we came across an example of resigned activism happening.

When visiting a local surf shop we met the owner, a semi-professional surfer named Riku (pseudonym). We discussed perceptions of radiation risk. I assumed he would be fearful of radiation. However, Riku had taken matters into his own hands. He told us how he had purchased his own handheld Geiger counter and conducted measurements, including at his favourite surf beach. The technology enabled him to sense what was beyond human sensory capabilities - a more-than-human sensibility and risk assessment of pollution. Riku found that radiation levels were what he and the Geiger counter deemed acceptable. His use of a Geiger counter was not uncommon. People bought and used cheap mass-produced consumer Geiger counters following the disaster (Matsutani, 2011). If used correctly (they tend to take 10 minutes to provide an accurate recording) they can provide guidance, however cheap mass-produced versions tend to have a high margin of error. Only expensive models can accurately detect alpha, beta, and gamma rays (Ibid). Nevertheless, the Geiger counter provided a 'scientific' mitigation of risk and uncertainty (and associated anxiety) that could be considered alongside competing and contradictory messages from various experts, the government, activists, and other residents (Kato, 2013). Surf shop owner - Keniche Funabe had also made decisions about risk in the midst of differential valuations. He explains, "I thought about it again and again but in the end, I became defiant. I was having a lot of stress from not being able to go back to the sea and it got to the point that this stress was becoming a greater health problem than the risk" (McClean, 2018, p. 71). The state of leisure and wellbeing enabled by the blue space overrides any possible declension of health. Polluted leisure involves negotiating valuations of risk, health, and wellbeing in blue spaces. It is, however, worth bearing in mind that gender has been found to shape risk perception and responses to the radiation post-disaster (Morioka, 2014). So it is possible that the men-who-surf we met do not want to talk too much about risk due to not wanting to be seen as mendokusai ("annoying" or a "troublemaker") (Ibid). Polluted leisure is gendered.

Following the visit with Riku, myself and one of the other research team members went surfing. I took a waterproof GoPro camera with me to record visuals and sound. When I panned the landscape from the sea, all I could see was an imposing 15-metre-high concrete seawall. Listening to the GoPro footage later, the sea sounded like a distorted snarling beast. It was very disorientating and unsettling to listen to, and quite different to the naturebased ambient sounds of the sea that have previously contributed to my own therapeutic accretion when surfing in 
blue spaces. The research team determined that the distortion was because the seawall acts as a sound mirror that amplifies and scrambles soundwaves. There was noise pollution. The seawalls interrupted any therapeutic leisure state available through an auditory experience. Polluted leisure is a multi-sensory embodied experience, and not just a cognitive one.

Japan has a long history of constructing such sea walls that function as extensive coastal protection structures to protect from tsunamis (Kimura, 2016). Post-3/11, a 10-year seawall construction project got underway to build $400 \mathrm{~km}$ of concrete seawalls (and heighten those already built) to protect communities from future tsunamis and make them feel safer (Lim, 2018). However, many seawalls had failed during the 2011 event due to a 'scour and soil instability' effect during the return-flow phase of the tsunami (Nateghi et al., 2016). After 3/11, government legislation recommended that the new seawalls need to be 10-15 metres in height and in some places almost double the width to be effective (Raby et al., 2015). The government has also put out media releases about the benefits of the seawalls.

In an article entitled "The white wall watching over the community", the walls are claimed to provide a sense of security (Shimizu, 2018). The media release notes how surfers find that the high seawalls provide an excellent vantage point to check the surf. Several people mentioned to one of the other researchers how beautiful it is to stand on top of the wall to see the "entire ocean." 17 This perspective supports the government's claim. Or perhaps it is a product of such a government-led discourse in the media? In some places, windows have been cut into the seawalls so people can look at the sea without having to climb them. We also noticed that some surfers benefitted from how the seawalls refracted swells into surfable waves and protected those waves from winds that would lower their quality. Further, some of the local surfers are employed by the construction industry that is building the seawalls. They would go surfing on their lunch break. I imagine for them it would be compromising to be dismissive of the seawall construction when it is part of a livelihood that enables them to go surfing.

The benefits of the seawalls are debated (Lim, 2018). Seaside communities protest seawall construction in Fukushima and elsewhere in Japan (Kimura, 2016; Lim, 2018). ${ }^{18}$ Some locals, including surfers, would prefer to rely on their own oceanic literacies developed over many generations to determine risk and safety. Kimura (2016) explains that "keeping the sea in sight is very important" to coastal villagers for practical, cultural, and spiritual reasons (p. 23). Local villages and towns with long-established and extensive surfing and fishing communities historically have a close relationship with the ocean. Some surfers mentioned how the walls cut them off from the ocean. The seawalls now co-author these blue spaces, popularly and unpopularly. And people are forced to develop complex relationships with industrial polluters and pollution. 
Concrete has been extensively used in Japan to change seashores, rivers, lakes, and wetlands. Japan’s ongoing rebuilding post World War Two has earned it the nickname doken kokka (construction state) (Watts, 2019). Concrete is part of these blue spaces. The concrete that makes up the seawalls is pollution. Concrete is the most abundant anthropogenic rock (Waters \& Zalasiewicz, 2018, p. 75). It is made by mixing cement, water, and aggregates such as gravel. The cement is produced by heating a granular substance known as 'clinker' while mixing it with different active ingredients. The mixture is cooled and ground up into powder form. Since the 20th century, concrete has included additives such as polymer fibres and plasticizers silica (Ibid, p. 84). Stajanča and Eštoková (2017) explain how

The production of cement involves the consumption of large quantities of raw materials, energy, and heat. Cement production also results in the release of a significant amount of solid waste materials and gaseous emissions. The manufacturing process is very complex, involving a large number of materials (with varying material properties), pyroprocessing techniques (e.g., wet and dry kiln, preheating, recirculation), and fuel sources (e.g., coal, fuel oil, natural gas, tires, hazardous wastes, petroleum coke). (p. 296)

The production of concrete accounts for 5-7\% of all human-generated CO2 emissions, not including its transportation (Ibid, p. 84). Production is water-intensive, making up one-tenth of the world's industrial water use. The mining of sand for cement production damages beaches and river courses. Further, concrete interrupts, changes, and destroys ecologies that support fertilisation, pollination, oxygen production, and water purification. Air pollution is also a significant by-product during production, causing acute dose-related respiratory problems near production sites for both workers and the wider populace (Moretti et al., 2017).

The construction of seawalls is understandable given the ever-present threat of tsunamis in Japan. While the cement, which is an ingredient of concrete, may not be manufactured in Fukushima, it calls attention to how blue spaces are never isolated. Health and wellbeing achieved through polluted leisure in 'this' blue space can be at the expense of others 'over there.' As Val Plumwood (2009) argues, there are "shadow places" that are "the multiple disregarded places of economic and ecological support" (n.p). Any benefits from blue spaces are going to be differentially distributed due to pollution.

\section{Conclusion}

This article has engaged with a health-led blue space discourse which argues that lakes, rivers, seas, oceans, etc. contribute to psychological, physical, emotional, and spiritual positive transformation. This can occur as a therapeutic accretion during leisure-orientated nature-based sports, such as surfing. However, as evidenced in this 
article, blue spaces are entangled with pollution (material and social). This means any benefits are going to be differentially distributed and circulated. Further, a more-than-human approach to understanding pollution unravels anthropocentric hubris that would enable us to determine health and wellbeing benefits achieved through 'a dose of nature', e.g. blue spaces. Along with accretion there may be declension during polluted leisure in blue spaces that are toxic natures (of varying harmfulness). For example, one may feel better emotionally after a surf while pollution that cannot be smelt or seen may be killing you, e.g. radiation, carcinogenic chemicals, etc. To varying degrees, everyone now has to negotiate blue spaces as toxic natures. The experience inculcates new skills, tasks, values, and orientations attached to shifting valuations, e.g. of risk, health, and wellbeing. Polluted leisure can end up entangled with a resigned activism. Finally, while any situated health, wellbeing, and therapeutic accretion may occur 'here' in 'this' blue space it is worth remembering that it is caught up with what is happening 'over there.' Pollution travels and is ecological. Given this, any nature-based sport is also pollution-based. They are polluted leisure.

Recognition of the relationship between polluted leisure and blue spaces could be understood as debilitating, depressing, apathetic, melancholic, and negative. It does, after all, undermine any blue space, sport, therapeutic, health, and wellbeing correlations. However, for me, insisting on the recognition of pollution is about what Donna Haraway (2015) calls 'staying with the trouble.' This refers to working through the toxic ruins and waste of capitalism, as well as challenging an Anglo-European separatist ontology/epistemology, to nurture alternative "ethical lifeways" (Osborne, 2019). These lifeways (which include leisure and sport) rest upon a premise of human and nonhuman co-existence and creation. Any salvaging of healthy human and nonhuman life is not going to proceed via some anthropocentric heroism. We alone cannot fix what we have broken (Tsing, 2015). Personally, I now realise I have much to learn from Indigenous Peoples who have survived following devastating violence, destruction, and trauma "even when we must piece those worlds together from gathered scraps" (Lee in Osborne, 2019, p. 147). My argument for registering polluted leisure as it relates to health, sport, wellbeing, therapy, and blue spaces is not simply a cynical intervention of negativity but also an attempt to open up a space for future research to locate and nurture ethical alternatives. I am sure subaltern possibilities already exist that provide a small taste of something better that can be learned from. So, hope has not been discarded even though pollution is going to have to be reckoned with.

\section{References}

Aarkog, A. (2003). Input of anthropogenic radionuclides into the World Ocean. Deep Sea Research Part II: Topical Studies in Oceanography, 50(17-21), 2597-2606. 
Anderson, J. (2009). Transient convergence and relational sensibility: Beyond the modern constitution of nature. Emotion Space and Society, 2(2), 120-127.

Anderson, J. M. (2012). Relational places: The surfed wave as assemblage and convergence. Environment and Planning D: Society \& Space, 30(4), 570-587.

Aoki, M. (2013, May 9). Fukushima activist fights fear and discrimination based on radiation. Japan Times. Retrieved from https://www.japantimes.co.jp/news/2013/05/09/national/fukushima-activist-fights-fear-and-discriminationbased-on-radiation/\#.XHprnIj7Q2x

Barad, K. (2007). Meeting the Universe Halfway: Quantum Physics and the Entanglement of Matter and Meaning. Durham, NC: Duke University Press.

Beck, U., \& Willms, J. (2004). Conversations with Ulrich Beck. Cambridge: Polity Press.

Bennett, J. (2004). The force of things: Steps toward an ecology of matter. Political Theory, 32(3), 347-372.

Bennett, J. (2010). Vibrant Matter. Durham, NC: Duke University Press.

Booth, D. (2018). Nature sports: Ontology, embodied being, politics. Annals of Leisure Research, online first. Retrieved from https://www.tandfonline.com/doi/full/10.1080/11745398.2018.1524306

Borne, G. (2018). Surfing and Sustainability. London: Routledge.

Braidotti, R. (2013). The Posthuman. Cambridge: Polity Press.

Britton, E. (2019). Duchas: Being and belonging on the borderlands of surfing, senses and the self. In R. Foley, R.

Kearns, T. Kistemann, \& B. Wheeler (Eds.), Blue Space, Health and Wellbeing: Hydrophilia Unbound (pp. 95-116).

London: Routledge.

Britton, E., Kindermann, G., Domegan, C., \& Carlin, C. (2018). Blue care: A systematic review of blue space interventions for health and wellbeing. Health Promotion International, 103, 1-20.

Brymer, E. (2009). Extreme sports as a facilitator of ecocentricity and positive life changes. World Leisure Journal, 51 , 47-53.

Brymer, E., \& Schweitzer, R. (2013). The search for freedom in extreme sports: A phenomenological exploration. Psychology of Sport and Exercise, 16(4), 865-873. 
Caddick, N., Smith, B., \& Phoenix, C. (2015). The effects of surfing and the natural environment on the wellbeing of combat veterans. Qualitative Health Research, 25, 76-86.

Chandler, D., \& Reid, J. (2016). The Neoliberal Subject: Resilience, Adaptation and Vulnerability. London: Rowman \& Littlefield.

Christoudias, T., \& Lelieveld, J. (2013). Modelling the global atmospheric transport and deposition of radionuclides from the Fukushima Dai-ichi nuclear accident. Atmospheric Chemistry and Physics, 13(3), 1425-1438.

Clapham, E., Armitano, C., Lamont, L., \& Audette, J. (2014). The ocean as a unique therapeutic environment: Developing a surfing program. Journal of Physical Education, Recreation and Dance, 85(4), 8-14.

Clough, P., Mackenzie, S., Mallabon, L., \& Brymer, E. (2016). Adventurous physical activity environments: A mainstream intervention for mental health. Sports Medicine, 46(7), 963-968.

Cohen, R., Baluch, D., \& Duff, L. J. (2018). Defining extreme sport: Conceptions and misconceptions. Frontiers in Psychology, 9, online. Retrieved from https://www.frontiersin.org/articles/10.3389/fpsyg.2018.01974/full Coole, D., \& Frost, S. (2010). New Materialisms: Ontology, Agency, and Politics. Durham, NC: Duke University Press. Crenshaw, K. (1989). Demarginalizing the intersection of race and sex: A black feminist critique of antidiscrimination doctrine, feminist theory and antiracist politics. University of Chicago Legal Forum, 140, $139-167$.

Dasgupta, S., Peng, X., Chen, S., Li, J., Du, M., Zhou, Y-H., Hong, G., Xu, H., \& Ta, K. (2018). Toxic anthropogenic pollutants reach the deepest ocean on Earth. Geochemical Perspectives Letters, 7. Retrieved from https://www.geochemicalperspectivesletters.org/article1814

Deleuze, G., \& Guattari, F. [1980] (2004). A Thousand Plateaus: Capitalism and Schizophrenia. London and New York: Continuum.

Douglas, M. (1966). Purity and Danger: An Analysis of Concepts of Pollution and Taboo. London: Routledge.

Evers, C. (2009). The point: Surfing, geography and a sensual life of men and masculinity on the Gold Coast, Australia. Social \& Cultural Geography, 10(8), 893-908.

Evers, C. (2016). Researching action sport with a GoPro ${ }^{\text {TM }}$ camera: An embodied and emotional mobile video tale of the sea, masculinity, and men-who-surf. In I. Wellard (Ed.), Researching Embodied Sport: Exploring Movement Cultures (pp. 145-162). London: Routledge. 
Evers, C. (2019). Polluted leisure. Leisure Sciences, online first. Retrieved from

https://www.tandfonline.com/doi/full/10.1080/01490400.2019.1627963

Foley, R. (2017). Swimming as an accretive practice in healthy blue space. Emotion, Space and Society, 22, 43-51.

Foley, R., Kearns, R., Kistemann, T., \& Wheeler, B. (Eds.). (2019). Blue Space, Health and Wellbeing: Hydrophilia Unbounded. Abingdon: Routledge.

Furnass, B. (1995). Survival health and wellbeing into the twenty first century. Proceedings of Nature and Society Forum Conference Australian National University Nov. 30-Dec. 1. Canberra, Australia: Nature and Society.

Gammon, S., \& Jarratt, D. (2019). Keeping leisure in mind: The intervening role of leisure in the blue space - health nexus. In R. Foley, R. Kearns, T. Kistemann, \& B. Wheeler (Eds.), Blue Space, Health and Wellbeing (pp. 38-51). Abingdon: Routledge.

Gascon, M., Zijlema, W., Vert, C., White, M. P., \& Nieuwenhuijsen, M. J. (2017). Outdoor blue spaces, human health and wellbeing: A systematic review of quantitative studies. International Journal of Hygiene and Environmental Health, 220, 1207-1221.

Gilchrist, P., \& Wheaton, B. (2016). Lifestyle and adventure sport amongst youth. In K. Green \& A. Smith (Eds.), Routledge Handbook of Youth Sport (pp. 186-200). London: Routledge.

Gilchrist, P., \& Wheaton, B. (2017). The social benefits of informal and lifestyle sports: A research agenda. International Journal of Sport Policy and Politics, 9(1), 1-10.

Grusin, R. (Ed.). (2015). Introduction. In The Nonbuman Turn (pp. i-xiii). Minneapolis, MN: University of Minnesota Press.

Haraway, D. (1991). Simians, Cyborgs and Women: The Reinvention of Nature. New York: Routledge.

Haraway, D. (2003). The Companion Species Manifesto: Dogs, People, and Significant Otherness. Chicago, IL: Prickly Paradigm Press.

Haraway, D. (2015). Anthropocene, capitalocene, plantationocene, chthulucene: Making kin. Environmental Humanities, 6, 159-165.

Haraway, D. (2016). Staying with the Trouble. Durham, NC: Duke University Press.

Harding, S. (2014). The Feminist Standpoint Theory Reader. New York: Routledge. 
Harding, A. K., Stone, D. L., Cardenas, A., \& Lesser, V. (2015). Risk behaviors and self-reported illnesses among Pacific Northwest surfers. Journal of Water and Health, 13(1), 230-242.

Hart, M. (2016, February 24). Surfing through sewage in South Africa. Vice Sports. Retrieved from https://sports.vice.com/en_uk/article/xybzdk/surfing-through-sewage-in-south-africa

Hartig, T., Mitchell, R., de Vries, S., \& Frumkin, H. (2014). Nature and health. Annual Review of Public Health, 35, $207-228$.

Humberstone, B. (2011). Embodiment and social and environmental action in nature-based sport: Spiritual spaces. Leisure Studies, 30(4), 495-512.

Ichii, Y. (2019). “Creative Reconstruction” and the 2020 Tokyo Olympic Games: How does the 2020 Tokyo Olympic Games influence Japan’s neoliberal social reform? International Journal of Japanese Sociology, 28(1), 96-109. Immonen, T., Brymer, E., Orth, D., Davids, K., Feletti, F., Liukkonen, J., \& Jaakkola, T. (2017). Understanding action and adventure sports participation-An ecological dynamics perspective. Sports Medicine - Open, 3(18). Retrieved from https://sportsmedicine-open.springeropen.com/articles/10.1186/s40798-017-0084-1

Ingersoll, K. A. (2016). Waves of Knowing: A Seascape Epistemology. Durham, NC: Duke University Press. Jones, A., \& Hoskins, T. (2016). Critical Conversations in Kaupapa Maori. Wellington: Huia Publishers.

Kato, K. (2013). As Fukushima unfolds: Media meltdown and public empowerment. In L. Lester \& B. Hutchins (Ed.), Environmental Conflict and the Media (pp. 201-214). New York: Peter Lang.

Kimura, S. (2016). When a seawall is visible: Infrastructure and obstruction in post-tsunami reconstruction in Japan. Science as Culture, 25(1), 23-43.

Krein, K. J. (2014). Nature sports. Journal of the Philosophy of Sport, 41(2), 193-208.

Lafforgue, E. (2016, August 29). Fukushima’s surfers riding on radioactive waves. Al Jazeera. Retrieved from https://www.aljazeera.com/indepth/inpictures/2016/08/fukushima-surfers-riding-radioactive-waves160826095748798.html Latour, B. (2005). Reassembling the Social: An Introduction to Actor-Network-Theory. Oxford: Oxford University Press. 
Leonard, A., Zhang, L., Balfour, A., Garside, R., Hawkey, P., Murray, A., Ukoumunne, O., \& Gaze, W. (2018). Exposure to and colonisation by antibiotic-resistant E. coli in UK coastal water users: Environmental surveillance, exposure assessment, and epidemiological study (Beach Bum Survey). Environment International, 114, 326-333.

Liboiron, M., Tironi, M., \& Calvillo, N. (2018). Toxic politics: Acting in a permanently polluted world. Social Studies of Science, 48(3), 331-349.

Lim, M. (2018, March 9). Seven years after tsunami, Japanese live uneasily with seawalls. Reuters. Retrieved from https://uk.reuters.com/article/us-japan-disaster-seawalls/seven-years-after-tsunami-japanese-live-uneasily-withseawalls-idUKKCN1GLODK

Lora-Wainwright, A. (2017). Resigned Activism: Living with Pollution in Rural Cbina. Cambridge, MA: The MIT Press.

Lorimer, H. (2005). Cultural geography: The busyness of being 'more-than-representational'. Progress in Human Geography, 29(1), 83-94.

Lorimer, J. (2010). Moving image methodologies for more-than-human geographies. Cultural Geographies, $17(2), 237-$ 258.

Maeda, M., \& Oe, M. (2017). Mental health consequences and social issues after the Fukushima disaster. Asia Pacific Journal of Public Health, 29(2_suppl), 36S-46S.

Martin, B., \& Davies, T. (2017). Towards nuclear geography: Zones, bodies, and communities. Geography Compass, 11(9). Retrieved from https://onlinelibrary.wiley.com/doi/full/10.1111/gec3.12325

Massumi, B. (2002). Parables for the Virtual: Movement, Affect, Sensation. Durham, NC and London: Duke University Press.

Matsutani, M. (2011, August 26). Spooked consumers snapping up cheap Geiger counters. Japan Times. Available at https://www.japantimes.co.jp/news/2011/08/26/business/spooked-consumers-snapping-up-cheap-geigercounters/\#.XSxTH-hKhaQ

McClean, C. (2018). Time will tell. Backwa.sh, 2, pp. 62-69.

McCurry, J. (2019, March 9). Surfers lead revival of Fukushima no-go beach. The Guardian, p. 39.

Miyazawa, K. (2018). Becoming an insider and an outsider in post-disaster Fukushima. Harvard Educational Review, 88(3), 334-354. 
Moretti, L., Di Mascio, P., \& Bellagamba, S. (2017). Environmental, human health and socio-economic effects of cement powders: The multicriteria analysis as decisional methodology. International Journal of Environmental Research and Public Health, 14(6), 645.

Morioka, R. (2014). Gender difference in the health risk perception of radiation from Fukushima in Japan: The role of hegemonic masculinity. Social Science \& Medicine, 107, 105-112.Muir, D. C. G., \& Rose, N. L. (2007). Persistent organic pollutants in the sediments of Lochnagar. In N. L. Rose (Ed.), Lochnagar: The Natural History of a Mountain Lake (pp. 375-402). Dordrecht: Springer.

Nateghi, R., Bricker, J. D., Guikema, S. D., \& Bessho, A. (2016). Statistical analysis of the effectiveness of seawalls and coastal forests in mitigating tsunami impacts in Iwate and Miyagi Prefectures. PlosOne. Retrieved from https://journals.plos.org/plosone/article?id=10.1371/journal.pone.0158375

Neal, T. (2016, April 4). Waves of disgust as surfers share sea with sewage. Radio New Zealand. Retrieved from https://www.radionz.co.nz/news/regional/300607/waves-of-disgust-as-surfers-share-sea-with-'sewage'

Neimanis, A. (2018). Queer times and chemical weapons, suspended in the Gotland Deep. Journal of Contemporary Archaeology, 5(1), 66-78.

Olive, R. (2016). Surfing, localism, place-based pedagogies, and ecological sensibilities in Australia. In B.

Humberstone, H. Prince, \& K. A. Henderson (Eds.), Routledge International Handbook of Outdoor Studies (pp. 501-510). Abingdon: Routledge.

Olive, R. (2019). Thinking the social through myself: Reflexivity in research practice. In B. Humberstone \& H. Prince (Ed.), Research Methods in Outdoor Studies (pp. 121-129). London: Routledge.

Osborne, N. (2019). For still possible cities: A politics of failure for the politically depressed. Australian Geographer, $50(2), 145-154$.

Panelli, R. (2010). More-than-human social geographies: Posthuman and other possibilities. Progress in Human Geography, 34(1), 79-87.

Pitt, H. (2018). Muddying the waters: What urban waterways reveal about bluespaces and wellbeing. Geoforum, 92, 161-170.

Plumwood, V. (2009). Nature in the active voice. Australian Humanities Review, 46, 113-129.

Probyn, E. (1993). Sexing the Self. New York: Routledge. 
Probyn, E. (2014). Women following fish in a more-than-human world. Gender, Place \& Culture: A Journal of Feminist Geography, 21(5), 589-603.

Probyn, E. (2016). Eating the Ocean. Durham, NC: Duke University Press.

Raby, A., Macabuag, J., Pomonis, A., Wilkinson, S., \& Rosetto, T. (2015). Implications of the 2011 Great East Japan Tsunami on sea defence design. International Journal of Disaster Risk Reduction, 14(4), 332-346.

Rojek, C. (1995). The Labour of Leisure. Cambridge: Sage.

Sanial, V., Buesslerm, M., Charette, A., \& Nagao, S. (2017). Unexpected source of Fukushima-derived radiocesium to the coastal ocean of Japan. Proceedings of the National Academy of Sciences. Retrieved from https://www.pnas.org/content/early/2017/09/26/1708659114

Shimizu, K. (2018, April 28). Shiroi kabe chiiki mimamoru [The white wall watching over the community]. Yomiuri Shinbun, p. 10 .

Stajanča, M., \& Eštoková, A. (2017). Environmental impacts of cement production. Retrieved from http://ena.lp.edu.ua:8080/bitstream/ntb/16692/1/55-Stajanca-296-302.pdf.

Stebbins, R. A. (2007). Serious Leisure: A Perspective for our Time. New Brunswick, NJ: Transaction Publishers.

Sundberg, J. (2014). Decolonizing posthumanist geographies. Cultural Geographies, 21, 33-47.

Takebayashi, Y., Lyamzina, Y., Suzuki, Y., \& Murakami, M. (2017). Risk perception and anxiety regarding radiation after the 2011 Fukushima nuclear power plant accident: A systematic qualitative review. International Journal of Environmental Research and Public Health, 14(11), 1306.

Taylor, B. (2007). Surfing into spirituality and a new aquatic religion. Journal of the American Academy of Religion, 75(4), 923-951.

Taylor, D. E. (2014). Toxic Communities: Environmental Racism, Industrial Pollution, and Residential Mobility. New York: New York University Press.

Thorpe, H., \& Chawansky, M. (2016). The 'Girl Effect' in action sports for development: The case of the female practitioners of Skateistan. In H. Thorpe \& R. Olive (Eds.), Women in Action Sport Cultures: Identity, Politics and Experience (pp. 133-152). London: Palgrave. 
Thorpe, H., \& Rinehart, R. (2013). Action sport NGOs in a neo-liberal context: The cases of Skateistan and Surf

Aid International. Journal of Sport and Social Issues, 37(2), 115-141.

Tsing, A. L. (2015). The Mushroom at the End of the World: On the Possibility of Life in Capitalist Ruins. Princeton, NJ:

Princeton University Press.

Vane, C. H., Beriro, D. J., \& Turner, G. H. (2015). Rise and fall of mercury (Hg) pollution in sediment cores of the

Thames Estuary London, UK. Earth and Environmental Science Transactions of the Royal Society of Edinburgh, 105, $285-296$.

Vannini, P. (Ed.) (2015). Non-representational Methodologies. London: Routledge.

Waters, C. N., \& Zalasiewicz, J. (2018). Concrete: The most abundant novel rock type of the Anthropocene. In D.

A. DellaSala \& M. I. Goldstein (Eds.), The Encyclopedia of the Anthropocene: Vol. 1 (75-85). Oxford: Elsevier.

Watts, J. (2019, February 25). Concrete: The most destructive material on Earth. The Guardian. Retrieved from https://www.theguardian.com/cities/2019/feb/25/concrete-the-most-destructive-material-on-earth

Whatmore, S. (2002). Hybrid Geographies. Natures, Cultures and Spaces. London: Sage.

Whatmore, S. (2006). Materialist returns: Practising cultural geography in and for a more-than-human world. Cultural Geographies, 13(4), 600-609.

Wheaton, B., Roy, G., \& Olive, R. (2017). Exploring critical alternatives for youth development through lifestyle sport: Surfing and community development in Aotearoa/New Zealand. Sustainability, 9(12), online. Retrieved from https://www.mdpi.com/2071-1050/9/12/2298/htm\#B69-sustainability-09-02298

World Health Organization (1946). Preamble to the Constitution of the World Health Organization as adopted by the International Health Conference, New York, 19-22 June 1946; signed on 22 July 1946 by the representatives of 61 States (Official Records of the World Health Organization, no. 2, p. 100) and entered into force on 7 April 1948.

World Health Organization (2012). Preliminary dose estimation from the nuclear accident after the 2011 Great East Japan Earthquake and Tsunami. Retrieved from https://www.who.int/ionizing_radiation/pub_meet/fukushima_dose_assessment/en/

Wright, S., Lloyd, K., Suchet-Pearson, S., Burarrwanga, L., Tofa, M., \& Bawaka Country (2012). Telling stories in, through and with Country: Engaging with Indigenous and more-than-human methodologies at Bawaka, NE Australia. Journal of Cultural Geography, 29(1), 39-60. 
Yang, C., Rose, N. L., Turner, B., Goldsmith, B., Losada, S., Barber, J. L., \& Harrad, S. (2016).

Hexabromocyclododecanes, polybrominated diphenyl ethers, and polychlorinated biphenyls in radiometrically dated sediment cores from English lakes, 1950-present. Science of the Total Environment, 541, 721-728.

\footnotetext{
${ }^{1}$ For a detailed account of what occurred see http://www.world-nuclear.org/informationlibrary/safety-and-security/safety-of-plants/fukushima-accident.aspx
}

${ }^{2}$ Leisure is notoriously difficult to define. I understand leisure here partially through a temporal model which describes it as "activities that take place during periods free from obligation" (Gammon \& Jarratt, 2019, p. 43). However, I note that leisure time does not necessarily equate to free time because the latter "can be both imposed and/or enforced" (Ibid). While leisure time can be imposed/enforced, enthusiasms/activities undertaken during it will still be volitional. It has been argued to be a temporary state of mind tied to a perceived freedom in action and decision, as well as a sense of doing something worthwhile, that "can be experienced at any time or place" (Ibid p. 44). Leisure is not simply something that happens outside of work. I emphasise the word 'perceived' because leisure is caught up in capitalist production. For example, surfers' practices, self-representations, emotional states, and enthusiasm are regularly co-opted, co-erced, and exploited to facilitate consumption and production, i.e. are made profitable. Capitalism has polluted leisure (Rojek, 1995). In addition, not everyone is free to engage with or enter into leisure in the same way due to varying socio-economic inequalities, e.g. gender, race, etc. Nonetheless, many leisure enthusiasts will continue to voluntarily participate.

${ }^{3}$ While the term 'sport' is often understood as equivalent to institutional structures, competition, clear goals, measurement, and formalised rules, I am adopting a broader definition here that understands it as an informal pastime without such qualities, and even disputing them (Krein, 2014; Gilchrist \& Wheaton, 2017). My emphasis here is on surfing as a sport when it equates to non-competitive leisure, rather than, say, competitive surfing. Other examples would be informal 'wild swimming,' windsurfing, scuba diving, canyoning, coasteering, fishing, and snowboarding (snowfields are arguably blue spaces too).

${ }^{4}$ These terms are often used interchangeably and, when they are not, definitions vary depending on academic disciplines and the emphasis of the researcher(s) e.g. on risk and danger, commercialism, commitment/belonging, media, socio-cultural codes, psychology, aesthetics, regulation and institutionalisation (also see competition), motivation, and more. For a helpful discussion about the various terms, debates about their usage, and their genealogies see Cohen et al. (2018). Enthusiasts of these sports tend to devote considerable commitment (e.g. time, money, thought, emotion, physical) to the activity. There is a privileging of unwritten cultural codes, aesthetics, and an "individualistic ideology that ... often denounces regulation and institutionalisation" and expresses an ambivalence about commercialism (Gilchrist \& Wheaton, 2016, p. 187). Examples of these sports are snowboarding, B.A.S.E jumping, freestyle BMX, mountain biking, bouldering, skateboarding, kiteboarding, rock climbing, parkour/free running, windsurfing, and surfing.

${ }^{5}$ When it comes to nature I am not excluding any 'artificial' built environment, which is actually part of nature. Any conceptual binary of artificial and nature is a social construction (Haraway, 2015).

${ }^{6}$ Health is agreed to be a "complete state of physical, mental and social wellbeing, and not merely the absence of disease or infirmity" (World Health Organization, 1946, p. 100). I understand the reference to wellbeing in this quote from the WHO to include "satisfactory human relationships, a meaningful occupation, opportunities for contact with the natural environment, creative expression, and making a positive contribution to human society" (Furnass, 1995, p. 6). 
${ }^{7}$ It is worth noting here how all the benefits reproduce a mantra of what the 'good' neoliberal subject should be seeking out and attempting to be, a language provided by late-stage capitalism (Chandler \& Reid, 2016). Again, capitalism has polluted leisure.

8 The more-than-human paradigm is also entangled with a number of other theoretical perspectives, such as posthumanism (Braidotti, 2013; Haraway, 1991), actor network theory (Latour, 2005), and new materialism (Coole \& Frost, 2010). However, I do not have space here to go into the similarities and differences.

${ }^{9}$ To understand agency through a more-than-human perspective it is helpful to proceed through a Deleuzian reading of the monist philosophy of Benedict Spinoza who understood this as affective. This affectivity refers to the mutual shaping of elements that result in "augmentation or diminution" of activity, capacity, and potential (Massumi, 2002, p. xvii). Agency is not understood as a possession of a thing or person because there is no essence to any 'body.' Rather, bodies are understood as 'assemblages,' localised inter- and intra-relations between heterogeneous elements that coalesce, mingle, and organise (Ibid). This concept has been arrived at through the work of Deleuze and Guattari (2004), it being a translation of the use in their work of the original French word agencement (which is a verb). Articulations - meanings, actions, values, forces - occur during the concrescence. Assemblages and their articulations are not fixed, as they are always 'becoming.'

${ }^{10}$ There are also overlaps with the work on 'multispecies companionship' by Donna Haraway (2003).

${ }^{11}$ It is important to acknowledge that while this more-than-human paradigm rooted in AngloEuropean philosophy may appear new to some of us, Indigenous scholars, storytellers, teachers, and seers have for a long time been proceeding from their own more-than-human ontologies and epistemologies that are "a space where objects can express their vitality—or, at least, where humans can experience their (objects') vitality" (Jones \& Hoskins, 2016, p. 85). See also Sundberg (2014); Wright et al. (2012). My scholarship here is not yet at a stage where I sufficiently understand Indigenous epistemologies and ontologies, nor do I have permission to employ them other than being guided by their experience and insights. So, I am proceeding with the Anglo-European more-than-human paradigm here.

${ }^{12}$ Future collaborative writing is to be forthcoming. This article is a reflection based on my experience, and no claims are made on behalf of the other research team members.

${ }^{13}$ Robert Stebbins (2007) developed the theoretical framework of 'serious leisure' to account for how sport and leisure can prompt significant enthusiasm and commitment in people, as well as high levels of diligence, purpose, and shared values.

${ }^{14}$ Surfing is to be part of the Tokyo 2020 Olympics. The video is propaganda for this (https://www.olympicchannel.com/en/original-series/detail/going-olympic-tokyo-2020/goingolympic-tokyo-2020-season-season-1/episodes/fukushima-returns-as-one-of-japan-s-premiersurf-spots/ Translation via https://www.surfer.com/videos/olympic-channel-highlightsfukushima-surfers/). While I could engage in a discussion about what local surfers think and feel about the Olympics and how this is now entangled with perceptions of the disaster and subsequent risk, this is beyond the scope of the article. That said, based upon informal conversations, interest in the Olympics was only mentioned in passing. There was a brief mention of a tension between how Tokyo surfers and those from Fukushima perceived any radiation risk, with the former being more concerned than the latter given that this group have been on the front lines of negotiating any perceived and potential actual risk. For an indicative examination of the 2020 Tokyo Olympic Games and how it connects to a national reconstruction policy adopted after the Great East Japan earthquake of 11 March 2011 see the work of Yoshifusa Ichii (2019).

${ }^{15}$ Wheaton et al. (2017) similarly encourage a reflexive criticality due to socio-cultural inequalities when it comes to associating lifestyle sports, social good, and blue spaces. They also discuss the problematic prevalence of a neoliberal ideology driving forward any lifestyle sport and social 
good agenda. However, Wheaton et al.'s discussion is principally about social change and development.

${ }^{16}$ When pollution is mentioned in regard to, say, surfing it is often framed through cultural politics and/or a sustainability discourse (for example, see Borne, 2018).

${ }^{17}$ Personal communication, 25 February 2019.

${ }^{18}$ For instance, see Save Katoku campaign (https://www.facebook.com/katokuhama/). 